\title{
Diversity and activity of bacterial biofilm communities growing on hexachlorocyclohexane
}

Ahmed Shawky Gebreil ${ }^{1,2}$ and Wolf-Rainer Abraham ${ }^{1 *}$

${ }^{1} \mathrm{HZI}$ - Helmholtz Centre for Infection Research, Chemical Microbiology, Braunschweig, Germany

${ }^{2}$ Lecturer of microbiology, Botany department, Faculty of Science, Mansoura University, Mansoura, Egypt

Running title: Biofilms growing on hexachlorocyclohexane

*Correspondence author: Dr. Wolf-Rainer Abraham, Chemical Microbiology, Helmholtz Centre for Infection Research, Inhoffenstraße 7, 38124 Braunschweig, Germany. Phone: 0049-531-6181-4300. Fax: 0049-5316181-4699. E-mail: wolf-rainer.abraham@helmholtz-hzi.de.

\section{Keywords:}

$\gamma$-hexachlorohexane, biofilm, degradation, community analysis, Firmicutes 


\begin{abstract}
$\gamma$-Hexachlorocyclohexane $(\gamma-\mathrm{HCH})$ persists in the environment and is recalcitrant to microbial degradation. To determine the extent of the microbial potential for the degradation of $\gamma-\mathrm{HCH}$ the diversity of bacteria from 12 soil samples collected around insecticide and pesticide producing factories in Egypt were assessed and compared with biofilm communities grown on $\gamma$-HCH microcrystals. From all samples highly diverse microbes were isolated, able to grow on $\gamma-\mathrm{HCH}$ as sole source of carbon. The same soil samples were used to inoculate $\gamma-\mathrm{HCH}$ microcrystals on a substratum in microcosms to grow biofilm communities. All soil samples formed multi-species biofilms on $\gamma-\mathrm{HCH}$

. Biofilms stained with Nile Red showed distinct cell clusters of high hydrophobicity and it is speculated that these aggregates have a substantial role in the degradation of the hydrophobic substrate. While many Bacillus species were isolated, this group was almost absent in the different biofilm communities. The finding of cells with highly hydrophobic envelopes together with the differences in species composition between isolates and interacting microbial communities point to fundamental differences in the interaction with hydrophobic substrates of single strains and microbial communities.
\end{abstract}

\title{
Introduction
}

Most bacteria living in the environment are organized in biofilms (Hall-Stoodley et al., 2004). A biofilm is an aggregate of microorganisms in which cells adhere to each other and/or to a surface. Biofilms can contain many different types of microorganism, e.g. bacteria, archaea, protozoa, and fungi; each group performing specialized metabolic functions. Biodegradation is a process whereby microbial communities contribute extensively to the attenuation, mineralization and transport of organic (carbon-based compounds) contaminants in the environment. The development of biofilms by microbial communities is often a key factor contributing to the overall efficiency of these processes. The potential of bioremediation (remediation using biological processes) as an alternative to physical and chemical remediation strategies has resulted in a significant amount of research effort on degradative biofilms. Biofilms have industrially been used, e. g. for bioremediation of hazardous materials and waste sites, biofiltration of industrial waste water or industrial air (Edwards and Kjellerup, 2013). There is ample evidence that microbial interactions are important for the functioning of microbial communities, especially when challenged with complex substrates (Macedo et al., 2005). Two key properties of degradative biofilms are: (1) the spatial organization of cells and (2) the establishment of a stable microenvironment through the production of extracellular polymeric substances (EPS). These characteristics promote the assemblage of larger and more diverse genetic pools in confined microniches, thereby expanding the range of substrates that can be degraded.

In this study the potential of biofilm communities and isolates, directly obtained from the same soil, for the degradation of $\gamma$-hexachlorocyclohexane $(\gamma-\mathrm{HCH})$ or lindane was assessed. $\mathrm{HCH}$ is insecticidal, toxic and considered as potential carcinogenic (Philipps et al., 2005). Due to persistence and recalcitrance, however, $\mathrm{HCH}$ continues to pose a serious toxicological problem at industrial sites where past production of lindane along with unsound disposal practices has led to serious contamination (Nayyar et al., 2014). In addition, many countries still allow $\mathrm{HCH}$ production and use despite localized limitations. Abiotic factors may degrade pesticides in soil or water 
ecosystem, however, the microorganisms present in soil and water are a major factor in the degradation of these pesticides (Singh et al., 2000). $\gamma$-HCH is degraded under both aerobic and anaerobic conditions, but it is mainly mineralized under aerobic conditions. Many $\gamma$-HCH-degrading aerobic bacteria have been isolated and characterized (Boltner et al., 2005; Lal et al., 2006; Mohn et al., 2006). Isolation of lindane-degrading microorganisms by enrichment culture has confirmed the ability of specific species of bacteria to degrade HCHs either aerobically or anaerobically (Alvarez et al., 2012). HCH-degrading Brevundimonas vesicularis P59 was isolated in the Netherlands (Bachmann et al., 1988) by enrichment culture from contaminated soil slurries. Sphingomonas paucimobilis UT26 is capable of aerobically degrading $\alpha-, \gamma$ - and $\delta$ - $\mathrm{HCH}$ isomers and using $\gamma-\mathrm{HCH}$ as a sole carbon source.

It can be assumed that in $\gamma$ - $\mathrm{HCH}$ polluted habitats not only single strains but bacterial consortia are adapted to this carbon source and that these consortia handle the pollutant differently to single strains. To gain access to these consortia biofilm communities derived from several soil samples were grown on $\gamma$-HCH microcrystals and their community composition was compared with strains obtained from the same soil and isolated on agar plates containing $\gamma-\mathrm{HCH}$ as sole carbon source.

\section{Materials and Methods}

Collection of soil samples. A total of twelve soil samples (approx. $50 \mathrm{~g}$ ) were collected from Egypt at different governorates located in the delta of the Nile (Alexandria (4 sites), Kafr El-Sheikh (1 site), Gharbia (1 site), Qalyubia (2 sites) and Monufia (4 sites)), around factories which produce chemicals, insecticides, and pesticides. The samples were collected in sterile plastic bags, homogenized and stored at $4{ }^{\circ} \mathrm{C}$ until use (Harry et al., 2000).

Isolation and purification of the $\boldsymbol{\gamma}$-HCH-degrading bacteria. One gram of soil was incubated in $250 \mathrm{ml}$ Erlenmeyer flasks containing $100 \mathrm{ml}$ of M9 medium (Sammbrook and Russell, 2001) with $\gamma$-HCH (2 mM) as the sole source of carbon and energy. After one month of cultivation at $30^{\circ} \mathrm{C}$ and shaking on a rotary shaker operated at $150 \mathrm{rpm}$, bacteria were isolated from soil through serial dilutions in PBS buffer. One hundred microliters of the dilution were spread onto M269 minimal medium (per litre: $2 \mathrm{~g}\left(\mathrm{NH}_{4}\right)_{2} \mathrm{SO}_{4} 100 \mathrm{mg} \mathrm{KCl}$, $500 \mathrm{mg} \mathrm{K} \mathrm{HPO}_{4}, 500 \mathrm{mg} \mathrm{MgSO}_{4} \times 7 \mathrm{H}_{2} \mathrm{O}$ ) agar plates supplemented with crystals of $\gamma-\mathrm{HCH}$ in the lid of the plate. After 7 days of incubation, colonies were picked and transferred to new plates by repeated subculturing and streaking on R2A medium or LB agar plates until pure cultures were obtained. For stock cultures a loop of a pure culture was added to $750 \mu$ sterile LB or R2A medium-depending on the isolate in a $2 \mathrm{ml}$ cryo-vial and incubated for one day at $30^{\circ} \mathrm{C}$. Then $500 \mu \mathrm{l}$ of sterile glycerol was added, the vial was mixed by vortexing and frozen at $-20^{\circ} \mathrm{C}$.

Sequencing of bacterial 16S rRNA genes. DNA was obtained for the amplification of the 16S rRNA gene by polymerase chain reaction by boiling single colonies in $100 \mu \mathrm{l}$ of TE buffer for about $10 \mathrm{~min}$. A nearly complete 16S rRNA gene sequence was obtained as described previously (Abraham et al., 1999). The reactions were evaluated on an Applied Biosystems 377 genetic analyzer and the final contig was assembled 
using the program SEQUENCHER ${ }^{\mathrm{TM}}$ Version 4.0.5 (Gene Codes Corporation, USA). The sequences together with those of the closest type strains were aligned using Clustal Omega software (Sievers et al., 2011) and the phylogenetic analysis was performed using MEGA 6 software (Tamura et al., 2013). Tree topologies were reconstructed with neighbour-joining algorithm with 1000 bootstrap replications using the sequences of type strains obtained from the EMBL database. The determined 16S rRNA gene sequences have been deposited in GenBank (accession numbers are given in figures 2-4).

Assessment of HCH-degradation of the isolates. Bacterial strains from frozen stock cultures were streaked on $\mathrm{R} 2 \mathrm{~A}$ or $\mathrm{LB}$ agar plates and incubated at $30^{\circ} \mathrm{C}$ until the formation of the colony was visible. Single colonies were inoculated in liquid culture (LB or R2A medium). The culture was incubated overnight in $100 \mathrm{ml}$ Erlenmeyer flasks with $20 \mathrm{ml}$ medium, $\mathrm{pH} 7.0$ at $30^{\circ} \mathrm{C}$ with orbital shaking at $150 \mathrm{rpm}$. To determine $\mathrm{HCH}$-degradation a volume of $300 \mu \mathrm{l}$ of the culture showing $\mathrm{OD}_{600}=0.5-0.7$ was transferred into $20 \mathrm{~m} 1$ of the minimal liquid culture (M269) which contain $2 \mathrm{mM}$ of $\gamma-\mathrm{HCH}$ as the sole carbon source. This culture was incubated at the same conditions and sampled every $24 \mathrm{~h}$ until day 9 . The bacterial cell density was quantified by measuring $\mathrm{OD}_{450}$ (Mosmann, 1983) and the viability of the cells was determined by using Water-soluble Tetrazolium salt (WST-1) reagent, starting at 0 incubation time. One hundred and sixty microliters of culture were incubated with $20 \mu \mathrm{l}$ of WST-1 in a 96-well plate for $30 \mathrm{~min}$ with shaking at $650 \mathrm{rpm}$ and at $30^{\circ} \mathrm{C}$. For negative control the strains were also inoculated in mineral medium without $\mathrm{HCH}$, no growth of these isolates was observed.

Microcosm experiments. About five grams of homogenised soil sample were placed in a $100 \mathrm{ml}$ stoppered glass vessel and $80 \mathrm{ml}$ of sterile tap water were added (Figure 1). Twenty $\mathrm{mg}$ of $\gamma-\mathrm{HCH}$ were dissolved in $1 \mathrm{ml}$ of dichloromethane (DCM). Droplets of $25 \mu \mathrm{l}$ of the $\gamma$ - $\mathrm{HCH}$ solution were placed on sterile Permanox ${ }^{\mathrm{TM}}$ (Nunc, USA) plastic slides $(100 \times 20 \mathrm{~mm})$ and DCM was allowed to evaporate. One slide, loaded with 8 droplets of the compound, was placed in the microcosm, sides with $\gamma$ - $\mathrm{HCH}$ crystals downwards facing the water surface of a reservoir. The microcosms were maintained at room temperature. The biofilm communities were harvested weekly with a sterile cotton swap from 4 spots of $\gamma-\mathrm{HCH}$ microcrystals, transferred to columns provided in the commercially available FastDNA ${ }^{\circledast}$ SPIN $^{\circledast}$ Kit for Soil (Bio 101, La Jolla, CA) according to the manufacturer's instructions. Pieces with 4 spots of $\gamma-\mathrm{HCH}$ microcrystals per slide were cut off and immediately examined by confocal laser scanning microscope (CLSM).

Single strand conformational polymorphism (SSCP) fingerprint analysis. The primers chosen for amplification of bacterial 16S rRNA genes were the forward primer Com1 (5'CAGCAGCCGCGGTAATAC3') and the reverse primer Com2-Ph (5'CCGTCAATTCCTTTGAGTTT3' with 5'-terminal phosphate group) as published (Schmalenberg et al., 2001). The phosphorylated strand of the PCR products was digested by lambda exonuclease (New England Biolabs, Schwalbach, Germany), proteins were removed by the Mini-elute kit (QIAGEN, Hilden, Germany) as recommended by the manufacturer, and the remaining single-stranded DNA was dried under vacuum. The DNA was then re-suspended in denaturing SSCP loading buffer (47.5\% formamide, $5 \mathrm{mM}$ sodium hydroxide, $0.12 \%$ bromophenol blue, and $0.12 \%$ xylene cyanol) and subjected to electrophoresis (Schwieger and Tebbe, 1998). 
Gels were run at $400 \mathrm{~V}$ for $17 \mathrm{~h}$ at $20^{\circ} \mathrm{C}$ in a Macrophor electrophoresis unit (LKB, Bromma, Sweden) and subsequently silver stained (Bassam and Gresshoff, 2007).

Sequence determination of SSCP bands. Bands were excised from the gel, eluted in buffer (10 $\mathrm{mM}$ Tris buffer, 5 $\mathrm{mM} \mathrm{KCl}, 1.5 \mathrm{mM} \mathrm{MgCl} \mathrm{ML}_{2} \cdot 6 \mathrm{H}_{2} \mathrm{O}, 0.1 \%$ Triton X-100, $\mathrm{pH} 9.0$ ), and extracted at $95^{\circ} \mathrm{C}$ for $15 \mathrm{~min}$. Extracts were centrifuged, and the supernatant was used as a DNA template in the PCR with the primers described above. The PCR product was purified (Mini-elute kit; QIAGEN, Hilden, Germany) and sequenced with a sequencing kit (DYEnamic ET Terminator cycle sequencing kit; Amersham Biosciences, Freiburg, Germany) and both primers. The product was cleaned with the Dye Ex Spin kit (QIAGEN, Hilden, Germany), and the sequence was analyzed on an ABI PRISM 337 DNA sequencer and an ABI PRISM 3100 genetic analyzer. The sequences were analyzed as described above.

Microscopy analysis - biofilm staining. Samples were stained with SYTO9 for nucleic acids (bacteria) and with Nile Red (Sigma, St. Louis, MO) for hydrophobic compounds (HCH, hydrophobic lipids) (Andrews et al., 2010). Cells were first stained with SYTO9 (Molecular Probes, Eugene, OR) for $10 \mathrm{~min}$, rinsed and then stained with Nile Red. For this purpose a stock solution of $2 \mathrm{mg}$ Nile Red in $1 \mathrm{ml}$ acetone-water (1:1, vol/vol) was diluted 1:1,000 in demineralized water. After staining for $15 \mathrm{~min}$, the sample was carefully rinsed twice. Alternatively, live and damaged cells in biofilms were stained with the BacLight kit (Molecular Probes) as described by the manufacturer. All samples were incubated in the dark and examined immediately after staining using CLSM. Laser scanning microscopy was performed using the model TCS SP attached to an upright microscope. The instrument was controlled by Leica Confocal software. The system was equipped with three visible lasers: an Ar laser (458, 476, 488, and $514 \mathrm{~nm})$, a laser iodide $(561 \mathrm{~nm})$, and a He-Ne laser $(633 \mathrm{~nm})$. The spectrophotometer feature allowed flexible and optimal adjustment of sliders on the detector side. The following settings were used for excitation and recording of emission signals (ex/em), respectively: Nile Red (488 and 550/700 nm), SYTO9 (488/500 nm) and propidium iodide $(490 / 635 \mathrm{~nm}$ ). Biofilm samples were observed with 10x 0.3-numerical aperture (NA), 20x0.5-NA, and $63 \times 0.9-\mathrm{NA}$ water-immersible lenses.

\section{Results and Discussion}

\section{Phylogeny and characteristics of bacterial isolates from Egyptian localities that were able to grow in the presence of $\gamma$-HCH}

The sequence of the 16S ribosomal RNA genes of the isolated strains from several localities, compared to the database of the National Centre for Biotechnology Information (NCBI) and sequences of their closest type strains (Euzéby, 2014), revealed the bacteria able to grow in the presence of $\gamma-\mathrm{HCH}$ as a nutrient. In the present study, 68 different bacterial strains were isolated from soil samples from Egyptian locations. Bacteria recorded in this investigation could be classified into 3 phyla: Proteobacteria, Firmicutes and Actinobacteria according to their 16S rRNA gene sequences. The phylum with the highest frequency was Proteobacteria, the phylum with moderate frequency and diversity was Firmicutes which contained the genera Bacillus, Oceanobacillus and Paenibacillus. The 
rarest phylum was Actinobacteria which contained 7 different species belonging to Agromyces, Gordonia, Microbacterium, Micromonospora, and Rhodococcus. The highest number of bacterial isolates was obtained from samples collected from the Monufia location and this was the only site heavily dominated by Bacillus species.

The Alexandria samples comprised a community which was mainly composed of the genera Achromobacter, Agromyces, Bacillus, Lysinibacillus, Microbacterium, Ochrobactrum, Pseudomonas, Rhodococcus and Starkeya. The phylogenetic tree showed the diversity and the bacterial relationship of these isolates (Figure 2). Contrary to the Alexandria site the bacterial communities of the Monufia samples were dominated by a broad diversity of Bacillus species (Figure 3). It was found that the bacterial strains which were isolated from Gharbia samples were again different from the previous samples. They consisted mainly of bacterial strains of the genera Aquamicrobium, Bacillus, Gordonia, Mesorhizobium, Micromonospora and Rhodococcus. Only three bacterial genera, Achromobacter, Lysobacter and Pseudomonas, could be identified in the Kafr El-Sheikh sample. From Qalyubia samples Bacillus, Brevundimonas, Luteimonas, Ochrobactrum, Pseudomonas, Rhodanobacter and Rhodococcus strains were isolated (Table 1).

\section{Growth of the bacterial isolates on $\gamma-\mathrm{HCH}$}

The metabolization and degradation of $\gamma-\mathrm{HCH}$ and bacterial growth was carried out for 15 days. Not all of the isolated bacterial species from soil samples grew well in the presence of $\gamma-\mathrm{HCH}$. Screening or selection of the most suitable bacterial species was based on the growth rate in the medium containing $\gamma-\mathrm{HCH}$. The results revealed that the most active bacterial isolates were Rhodococcus ruber Qalyubia2S12, Pseudomonas balearica Alexandria4S10, Bacillus sp. Monufia7S7, Mesorhizobium shangrilense Gharbia4S11 and Lysobacter daejeonensis Kafr3S9. Growth of Rhodococcus ruber Qalyubia2S12 reached its maximum after the $2^{\text {nd }}$ day of cultivation. Pseudomonas balearica Alexandria4S10, Bacillus sp. Monufia7S7 and Mesorhizobium shangrilense Gharbia4S11 gradually reached their maximum at $3^{\text {rd }}$ day of incubation. The growth of Lysobacter daejeonensis Kafr3S9 was at its maximum after the $4^{\text {th }}$ day of cultivation. After that the growth of all isolates gradually decreased over time (Figure 4). The species found here to grow best in the medium containing $\mathrm{HCH}$ as sole carbon source are different to the ones usually used to study $\mathrm{HCH}$ degradation. Sahu et al. studied the degradation of $\gamma-\mathrm{HCH}$ by a Pseudomonas sp. isolated from sugarcane rhizosphere soil. The authors demonstrated the almost complete disappearance of the pesticide within 24 $\mathrm{h}$ of incubation with a concomitant release of $\mathrm{Cl}^{-}$almost in stoechiometric amounts (Sahu et al., 1990). Lindane was totally consumed within $72 \mathrm{~h}$ by a consortium of bacteria isolated from a river sediment (Benimeli et al., 2006). Further work is needed to characterize the degradation pathways and the optimal conditions for $\mathrm{HCH}$ degradation for any of the above isolates.

\section{Analysis of bacterial biofilm community compositions developing on $\gamma$-HCH microcrystals}

After isolation and identification of the most active degraders for $\gamma-\mathrm{HCH}$, the objective of the present work was to compare the diversity and activity of the isolates with microbial biofilm communities colonizing $\gamma$-HCH crystals. Microbial communities organized in biofilms show a multitude of interactions, including carbon sharing (Nielsen et 
al., 2000), interspecies communication (Schachter, 2003), and steep physicochemical gradients and are very well protected against environmental stress factors such as toxic compounds, water stress, or grazing (Matz et al., 2004). To take advantage of the special conditions in biofilms, soil samples were taken as inocula to grow biofilm communities on the pollutant. Biofilms developing on the $\gamma-\mathrm{HCH}$ microcrystals were harvested at different time points $(7,14,21,28,35$ and 42 days). To allow a fast overview over the diversity of biofilm communities and their dynamics 16S rRNA gene fingerprinting using SSCP was applied. SSCP community profiling showed highly diverse and distinct bacterial communities for $\gamma-\mathrm{HCH}$ microcrystals with biofilm from the soil samples. Although some changes could be seen the majority of species in the biofilm communities remained constant as the bands in the SSCP profiles remained constant over time (Figure 5). Analysis of bacterial biofilm structure from Alexandria location by SSCP revealed considerable diversity in the bacterial communities. By comparing the sequences of 11 excised bands, 8 different operational taxonomic units (OTUs) could be identified. The phylogenetic tree (Figure 5) presents the closest related species to each sequence obtained. The majority of the identified OTUs were members of the phylum Alphaproteobacteria followed by Betaproteobacteria and Gammaproteobacteria.

For all samples it was possible to grow biofilms on the $\mathrm{HCH}$ crystals and the individual biofilm communities differed considerably between the different sites, a phenomenon already described for other biofilm communities (Macedo and Abraham, 2009). This underlines that different communities are capable of HCH degradation and that probably conditions specific for the site control community composition as has been shown before in the case of PCB degradation (Macedo et al., 2007). From bacterial biofilm communities 38 operational taxonomic units (OTUs) were identified. Fifteen OTUs belonged to the phylum Proteobacteria but the phyla Firmicutes and Cyanobacteria contained only one OTU each. Sphingomonas, Serratia, Pseudomonas and Burkholderia were the most frequent genera. The members of the individual biofilm communities turned out to be different from those isolated through classical microbiological methods from the same soil samples. This again underlines both the strong selection pressure applied by isolation and the tight interactions between different species in such biofilm communities.

This is an interesting finding because most of the $\mathrm{HCH}$-degrading aerobic bacterial strains reported until now are gram-negative and members of the family Sphingomonadaceae. A few other HCH-degrading isolates such as Rhodanobacter lindaniclasiticus and Xanthomonas sp. were also reported (Nalin et al., 1999). Only very few grampositive strains, such as Microbacterium sp. and Bacillus sp., have been shown to degrade HCH (Elcey and Kuhni, 2010). Previous studies have demonstrated that the individual strains do not act isolated from the other community members but have strong interactions with each other (Pelz et al., 1999). A simple comparison of the isolates with the activity of the biofilm communities is therefore not possible. Furthermore, a mere combination of the isolates is not feasible to gain activities and robustness comparable to the one observed in the biofilms. Probably other techniques as meta-transcriptomics or stable isotope analyses are required to get a much deeper understanding of $\mathrm{HCH}$ degradation in biofilms communities (Tillmann et al., 2005). 


\section{Structure of the biofilm changes along the pollution gradient}

The biofilm originating from soil sample was treated with Live/Dead stain to determine the rate of live to damaged cells over 42 days and it was found that damaged cells could be preferentially found on the HCH-crystals and towards the end of the experiment. After 7 days of incubation a biofilm was detected on the Permanox ${ }^{\mathrm{TM}}$ slide close to the crystals but only few cells were observed on the crystals directly. Subsequently, after 14 days a substantial biofilm accumulation on the margins of the pollutant was observed. Furthermore, after 14 days the number of live cells was higher than those of the defective cells. After 21 days when the biofilm showed the highest number of species in the SSCP profiles large microbial aggregates encircling the microcrystals of $\gamma-\mathrm{HCH}$ could be seen. Twenty-eight days after incubation, the bacterial population on the Permanox ${ }^{\mathrm{TM}}$ substratum was somewhat reduced and the crystals started to break up. The 35 and 42 days old biofilms revealed the dominance of damaged cells and the complete disappearance of the $\gamma-\mathrm{HCH}$ crystals. Finally, the aggregates of pollutants almost disappeared and almost all cells were damaged. One reason could be metabolites inhibiting or damaging cells in the biofilm leading to a higher ratio of damaged to living cells (Macedo et al., 2005).

In order to follow the dynamics in biofilm architecture the biofilm was also monitored using the hydrophobic dye Nile Red and, interestingly, this dye stained also some aggregates of bacteria indicating highly hydrophobic cell surfaces (Figure 1). The role of these highly hydrophobic microcolonies in the degradation process is not clear. One can speculate that these microcolonies are the ones preferentially taking up $\mathrm{HCH}$ for the initial degradation step and nourish the less hydrophobic microcolonies with intermediates.

Generally, the bacterial biofilms in the $2^{\text {nd }}$ and $3^{\text {rd }}$ weeks were more prominent and diverse, but remained relatively constant in the $4^{\text {th }}$ week and no new significant SSCP bands appeared. In the 5 and 6 weeks old biofilms, most of the microbial communities changed. The $\mathrm{HCH}$ crystals were never heavily colonized by bacteria, instead they were surrounded by bacteria probably taking advantage of the diffusion gradient of $\mathrm{HCH}$ dissolving in water. An astonishing phenomenon is the fragmentation and dissolution of the $\mathrm{HCH}$ microcrystals at the end of the experiment which was not seen before in any of these microcosms. Microcosms are closer to the situation in the field than isolated microorganisms; however, they are still not the same than the situation in situ. Nevertheless, valuable insights into the degradation process by microbial communities and its dynamics can be gained by such experiments. The discovery of highly hydrophobic microcolonies is one example.

\section{Conclusions}

Among the isolates found using $\mathrm{HCH}$ as carbon source, Bacillus, Pseudomonas and Rhodococcus were the most frequent and diverse genera and their species have been reported frequently to grow on $\gamma-\mathrm{HCH}$. However, some rare genera were also among the isolates (e.g. Achromobacter, Cupriavidus, Starkeya). The study presented here enlarges the number of genera and species able to use $\mathrm{HCH}$ offering novel possibilities in using bacteria for $\mathrm{HCH}$ degradation. The results of our study revealed diverse microbial communities in Egyptian soil samples which were able to colonize $\gamma$-HCH crystals. Remarkable is the large dichotomy between the taxonomic composition of the 
isolates and the species detected in the biofilm community growing on $\mathrm{HCH}$-crystals. This highlights two facts: that still a number of bacteria species are difficult to isolate and that different species interact in biofilm communities achieving the degradation of recalcitrant substrates. This is supported by the detection of highly hydrophobic microcolonies with in the biofilm and we speculate that these microcolonies have a key role in the degradation process within the biofilm.

The method applied was very effective in selecting communities of $\gamma$-HCH degraders, which could metabolize its microcrystals. Despite the fact that some members of the communities disappeared during incubation, the most abundant members tend to stay over time. The approach used proved to be a good method to follow the dynamics of biofilm communities composed of uncultured bacteria. The current work on the diversity of $\mathrm{HCH}$ degraders and their dynamics in the biofilm communities is therefore a step forward in understanding the role of different microorganism and their communities in the degradation of $\mathrm{HCH}$. The findings presented here support and help to optimize in situ bioremediations using biofilm communities.

\section{Acknowledgements}

We are indebted to Jennifer Skerra and Esther Surges for all their help in the laboratory and to Dr. Maximiliano G. Gutierrez for his efforts in the microscopic studies. A.S.G. acknowledges a Ph.D. stipend from the Egyptian mission government.

Conflict of interest: The authors declare that they have no conflict of interest. 


\section{Figure legends}

Figure 1 Left: Scheme of the microcosm used to grow biofilms; right: Biofilm grown from the Gharbia sample after 7 days on $\gamma$-HCH microcrystals stained with SYTO9 (green) and Nile Red showing areas with medium hydrophobicity in yellow and high hydrophobicity in red. A $\gamma$-HCH microcrystal can be seen in the lower right corner of the micrograph. Grid size $=20 \mu \mathrm{m}$

Figure 2 Phylogeny of bacterial isolates from Alexandria samples able to grow on $\gamma$-HCH and their closest type strains (Neighbor joining clustering of 16S rRNA gene sequences; GenBank acc. no. in brackets; outgroup: Ferroplasma acidiphilum DSM $12658^{\mathrm{T}}$ [AJ224936]). Bar represents 2\% sequence dissimilarity

Figure 3 Phylogeny of bacterial isolates from Monufia samples able to grow on $\gamma$-HCH and their closest type strains; GenBank acc. no. in brackets; outgroup: Ferroplasma acidiphilum DSM 12658 ${ }^{\mathrm{T}}$ [AJ224936]. Bar represents $2 \%$ sequence dissimilarity. The high prevalence of Bacillus isolates compared to the Alexandria samples (Figure 2) is striking

Figure 4 Growth curves of isolates on M269 medium with $\gamma$-HCH as sole carbon source. Rhombus: Mesorhizobium shangrilense Gharbia4S11, circle: Pseudomonas balearica Alexandria4S10, triangle: Bacillus sp. Monufia7S7, square: Lysobacter daejeonensis Kafr3S9, diamond: Rhodococcus ruber Qalyubia2S12. All these strains had their maximum after around 2 days after inoculation and then $\mathrm{OD}_{450}$ slowly decreased

Figure 5 Composition of $\gamma-\mathrm{HCH}$ bacterial biofilm communities obtained from two soil samples from Qalyubia analyzed by $16 \mathrm{~S}$ rRNA gene based community fingerprint (SSCP). Numbers on top of the gel correspond to sampling time in weeks and lanes $\mathrm{M}$ show the marker; numbered bands in the gel belong to OTUs shown in the phylogenetic tree. The phylogenetic tree based on the sequences of the SSCP bands differs considerably from the isolates from the different sites (Figures 2 and 3). Bar represents 0.02 substitutions per nucleotide position 


\section{Figure 1}
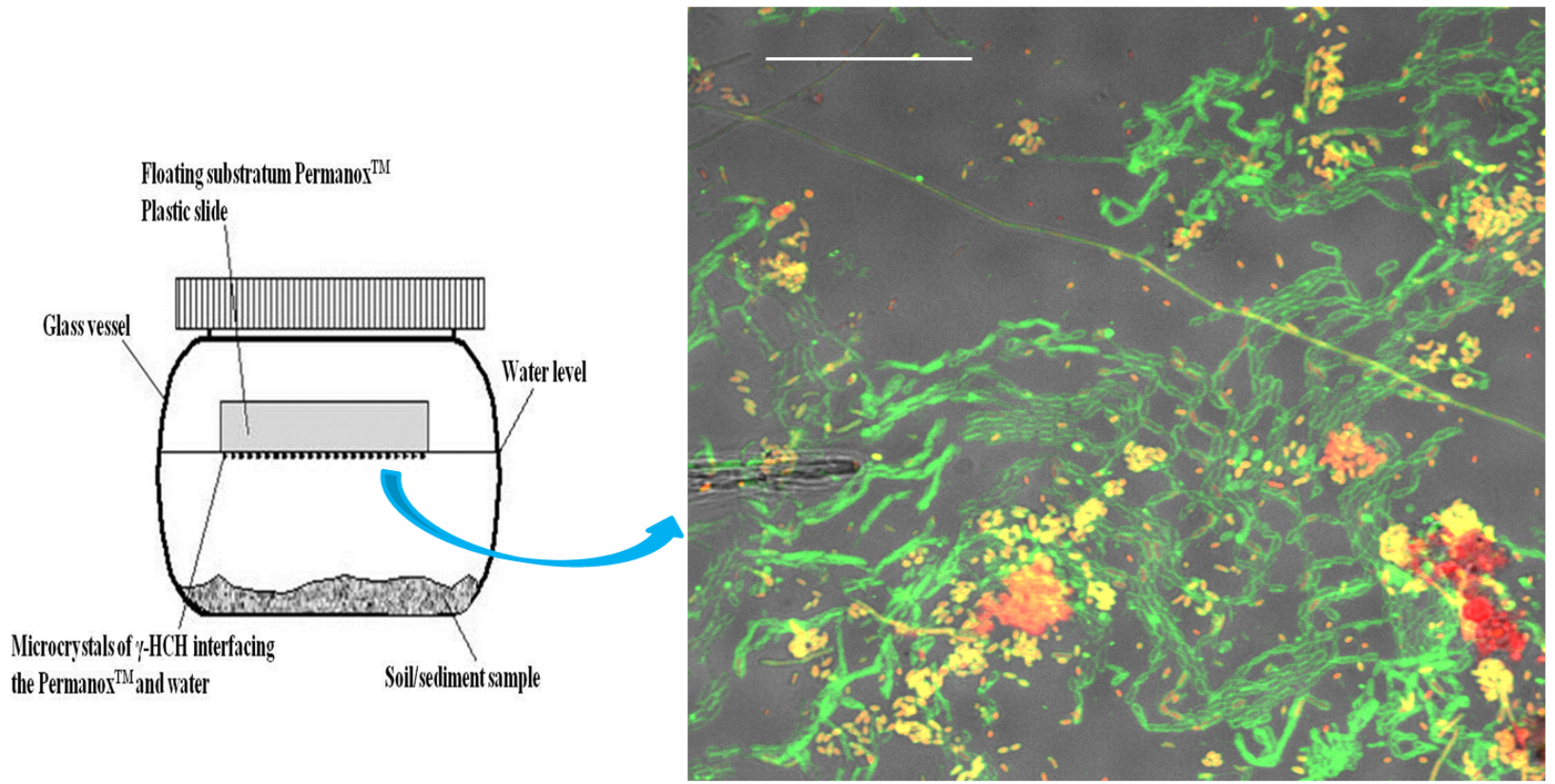
Figure 2 


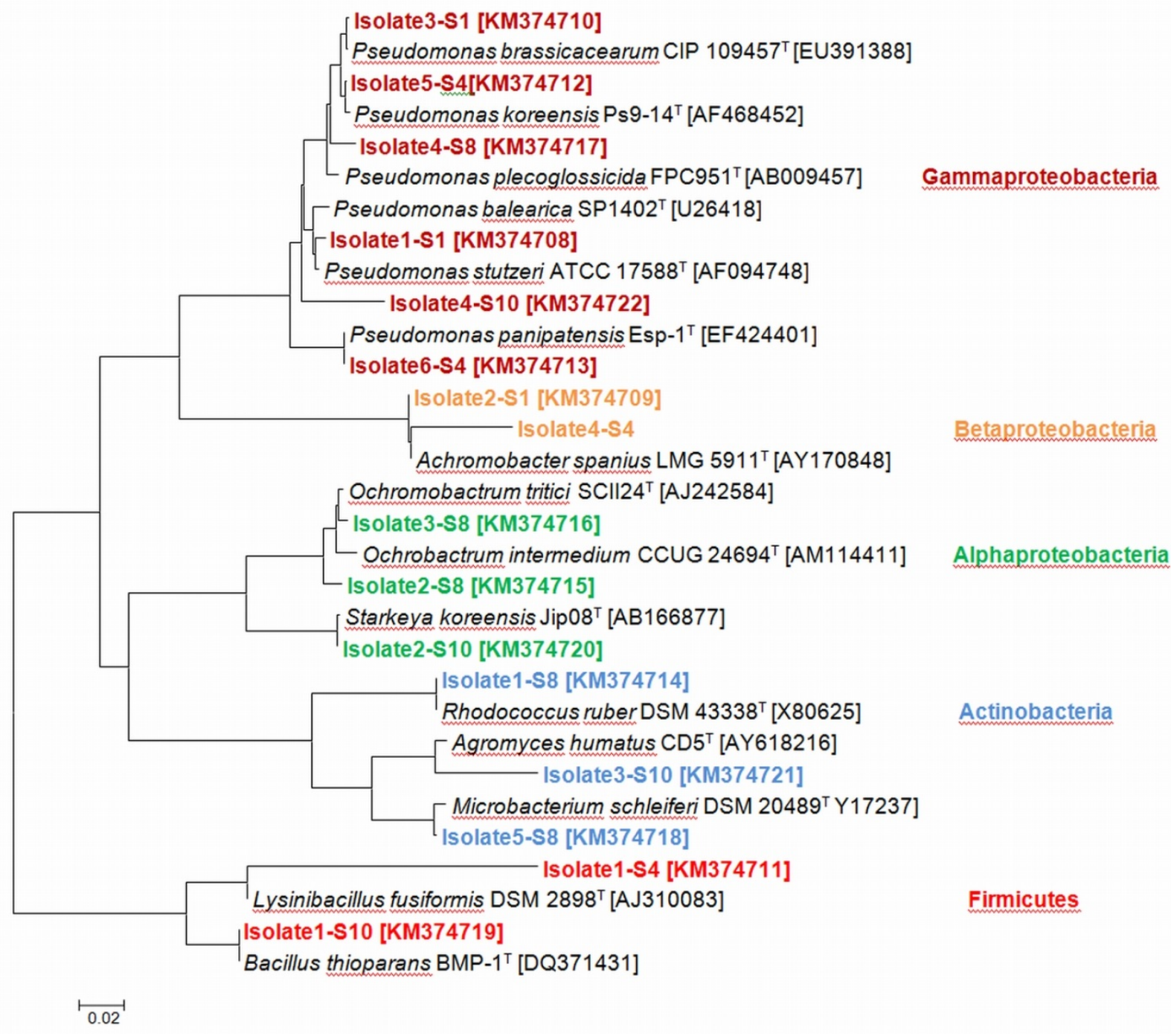

gure 3 


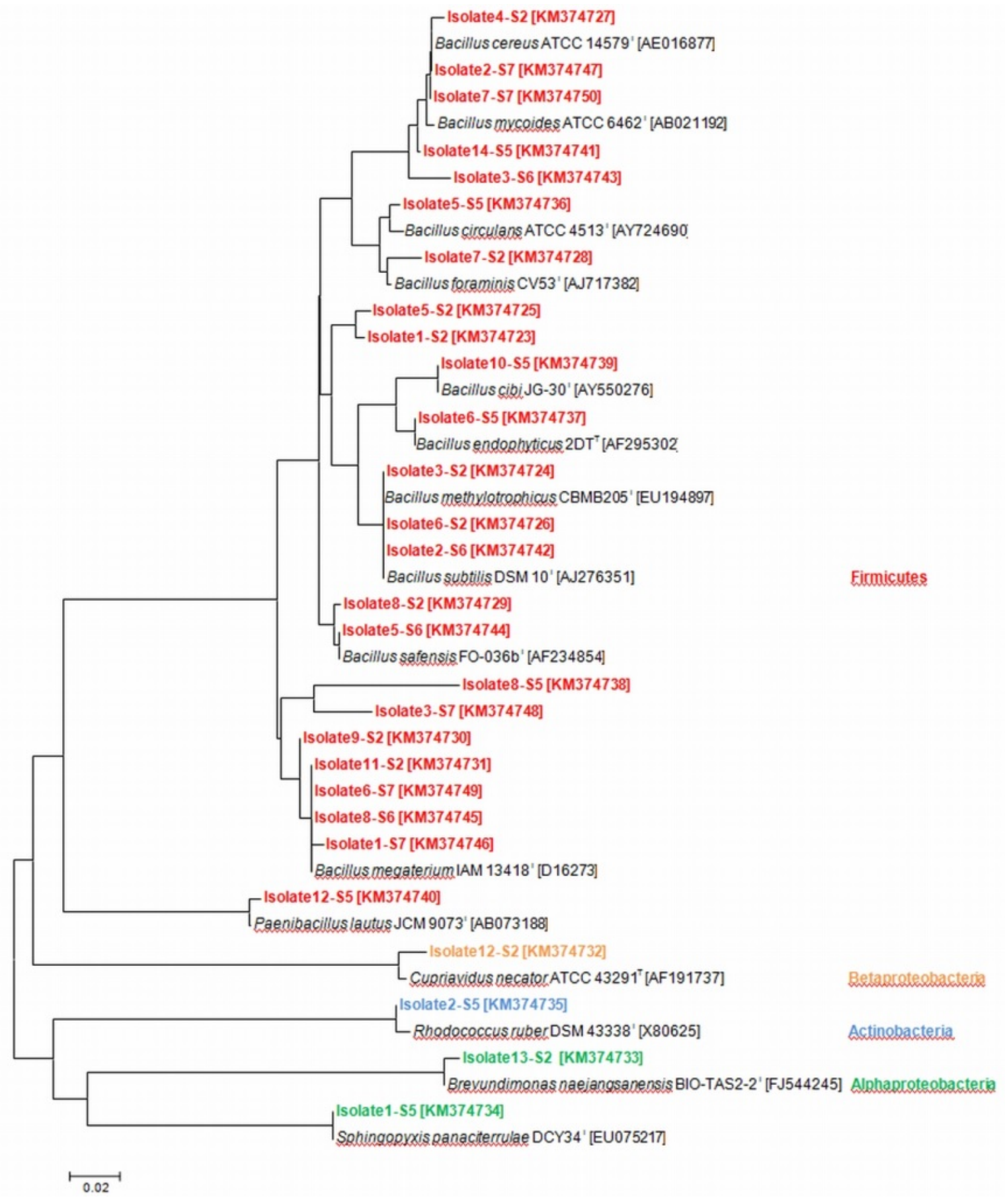


Figure 4

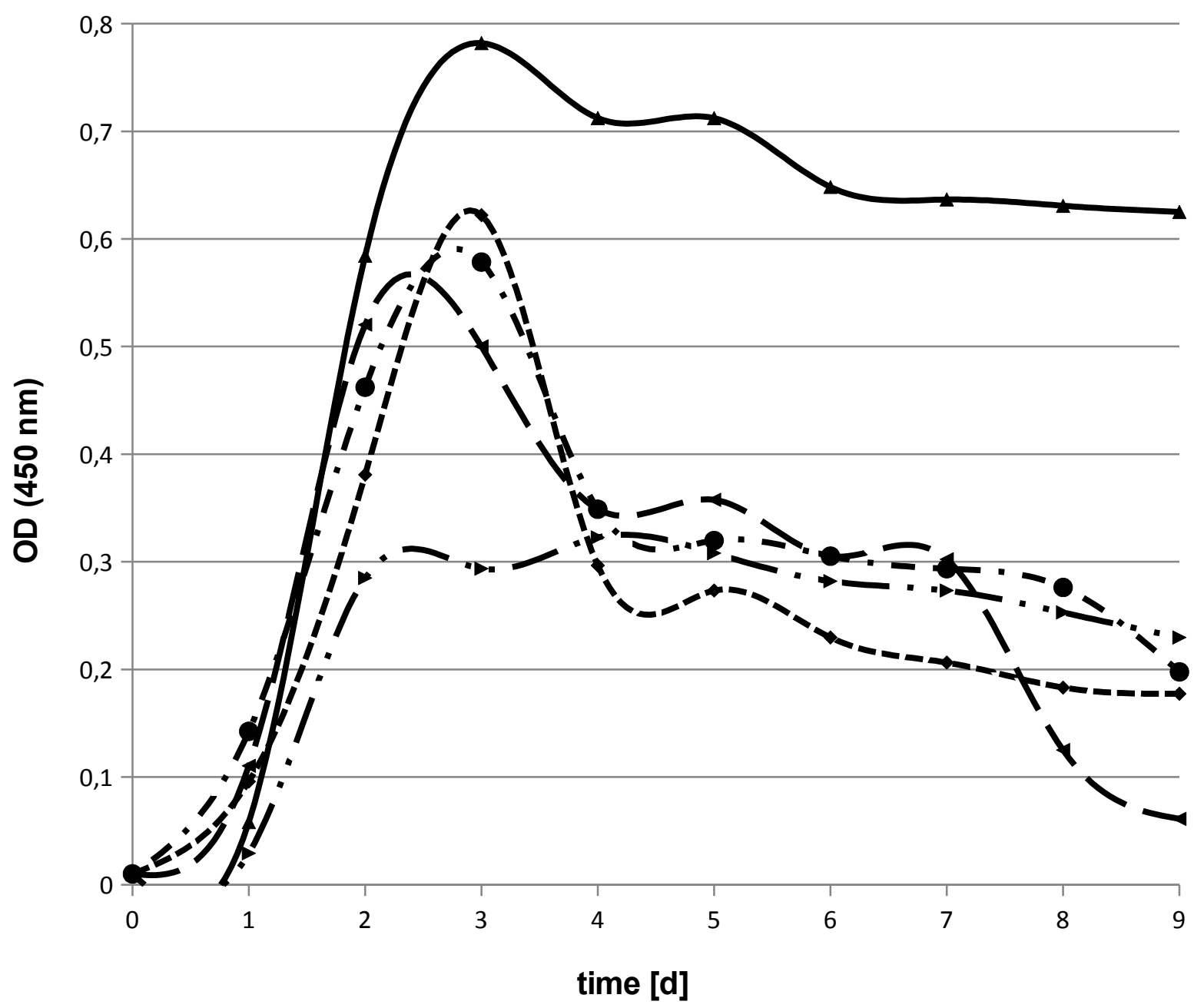


Figure 5

Qalyubia 2

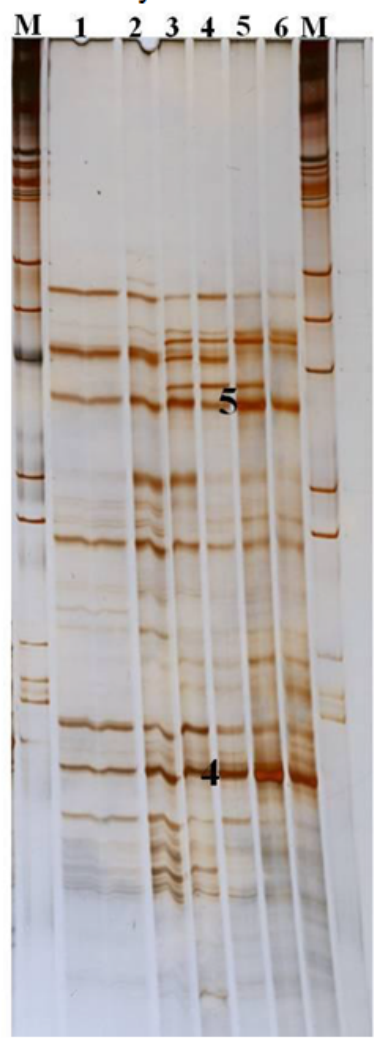

Qalyubia 1

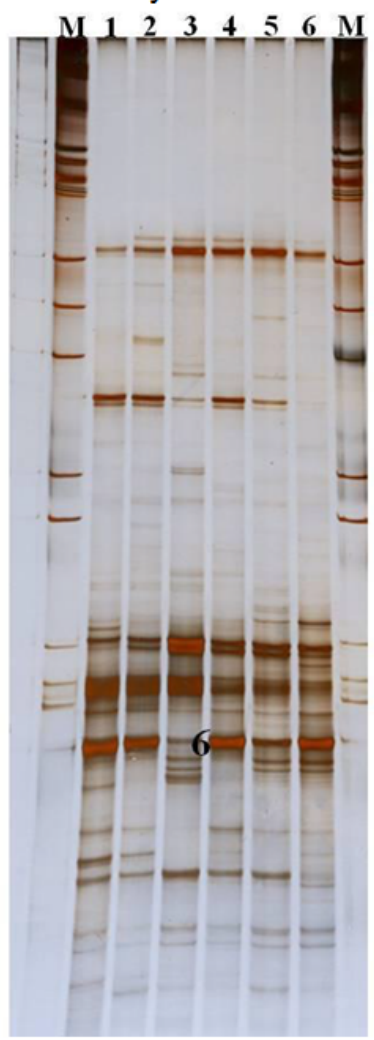

-Monufia2-7

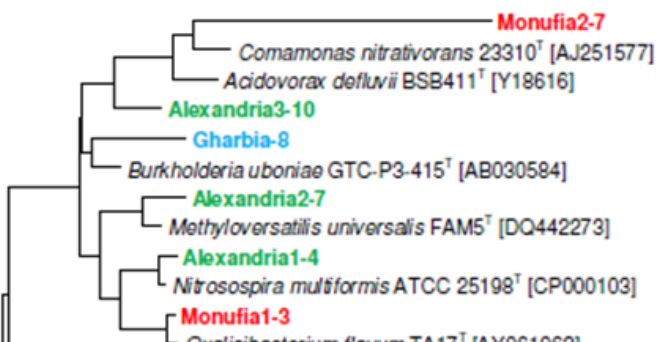

Monufia1-3

Oxalicibacterium flavum TA17 ${ }^{\top}$ [AY061962

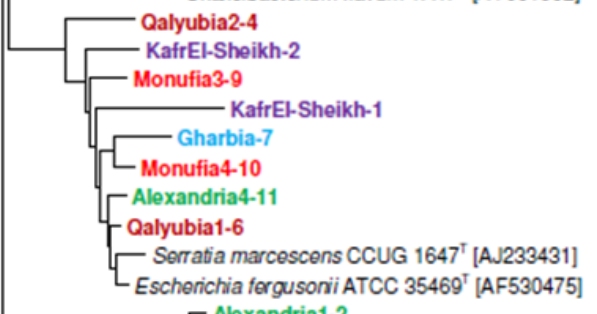

Alexandria1-2
Psoudomonas pell R-20805 ${ }^{\mathrm{T}}$ [AM114534]
Pseudomonas fluorescons RH818 Alexandria1-3

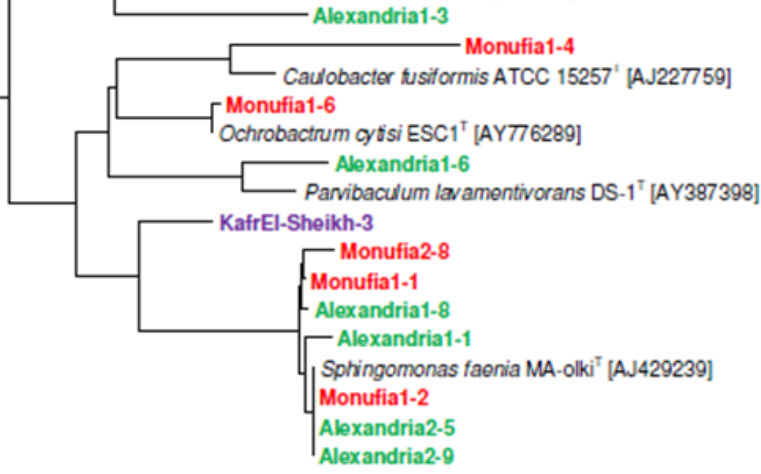




\section{References}

Abraham, W.-R., Strömpl, C., Meyer, H., Lindholst, S., Moore, E. R. B., Bennasar, A., Christ, R., Vancanneyt, M., Tindall, B., Smit, J., Tesar, M. (1999). Phylogeny and polyphasic taxonomy of Caulobacter species. Proposal of Maricaulis gen. nov. with M. maris (Poindexter) comb. nov. as type species and emended description of Caulobacter and Brevundimonas. Int. J. Syst. Microbiol., 49, 1053-1073.

Alvarez, A., Benimeli, C. S., Saez, J. M., Fuentes M. S., Cuozzo, S. A., Polti, M. A., Amoroso, M. J. (2012).

Bacterial bio-resources for remediation of hexachlorocyclohexane. Int. J. Mol. Sci., 13, 15086-15106.

Andrews, J. S., Rolfe, S. A., Huang, W. E., 花holes, J. D., Banwart, S. A. (2010). Biofilm formation in environmental bacteria is influenced by different macromolecules depending on genus and species. Environ. Microbiol., 12,2496-2507.

Bachmann, A., Walet, P., Wijnen, P., De Bruin, W., Huntjens, J. L., Roelofsen, W., Zehnder, A. J. (1988). Biodegradation of alpha- and beta-hexachlorocyclohexane in a soil slurry under different redox conditions. Appl. Environ. Microbiol., 54, 143-149.

Bassam, B. J., Gresshoff, P. M. (2007). Silver staining DNA in polyacrylamide gels. Nat. Protoc. 2, $2649-2654$.

Benimeli, C. S., Castro, G. R., Chaile, A. P., Amoroso, M. J. (2006). Lindane removal induction by Streptomyces sp. M7. J. Basic Microbiol., 46, 348-357.

Boltner, D., Moreno-Morillas, S., Ramos, J. L. (2005). 16S rDNA phylogeny and distribution of lin genes in novel hexachlorocyclohexane-degrading Sphingomonas strains. Environ. Microbiol., 7, 1329-1338.

Edwards, S. J., Kjellerup, B. V. (2013). Applications of biofilms in bioremediation and biotransformation of persistent organic pollutants, pharmaceuticals/personal care products, and heavy metals. Appl. Microbiol. Biotechnol., 97, 9909-9921.

Elcey, C. D., Kunhi, A. A. (2010). Substantially enhanced degradation of hexachlorocyclohexane isomers by a microbial consortium on acclimation. J. Agric. Food Chem., 58, 1046-1054.

Euzéby, J. P. (2014). List of prokaryotic names with standing in nomenclature. www.bacterio.net

Hall-Stoodley, L., Costerton, J. W., Stoodley, P. (2004). Bacterial biofilms: From the natural environment to infectious diseases. Nat. Rev. Microbiol., 2, 95-108.

Harry, M., Gambier, B., Garnier-Sillam, E. (2000). Soil conservation for DNA preservation for bacterial molecular studies. European J. Soil Biol., 36, 51-55.

Lal, R., Dogra, C., Malhotra, S., Sharma, P., Pal, R. (2006). Diversity, distribution and divergence of lin genes in hexachlorocyclohexane-degrading sphingomonads. Trends Biotechnol., 24, 121-130. 
Macedo, A. J., Abraham, W.-R. (2009). Microcosms for biofilm analysis on hydrophobic substrates - A multiple approach to study biodiversity, metabolic activity and biofilm structure and dynamic. In K. N. Timmis (Ed.), Handbook of hydrocarbon microbiology: Microbial interactions with hydrocarbons, oils, fats and related hydrophobic substrates and products (pp. 3544-3551). New York: Springer.

Macedo, A. J., Kuhlicke, U., Neu, T. R., Timmis, K. N., Abraham, W.-R. (2005). Three stages of a biofilm community developing at the liquid-liquid interface between polychlorinated biphenyls and water. Appl. Environ. Microbiol., 71, 7301-7309.

Macedo, A. J., Timmis, K. N., Abraham, W.-R. (2007). Widespread capacity to metabolize polychlorinated biphenyls by diverse microbial communities in soils with no significant exposure to PCB contamination. Environ. Microbiol., 9, 1890-1897.

Matz, C., Bergfeld, T., Rice, S. A., Kjelleberg, S. (2004). Microcolonies, quorum sensing and cytotoxicity determine the survival of Pseudomonas aeruginosa biofilms exposed to protozoan grazing. Environ. Microbiol., 6, 218-226.

Mohn, W. W., Mertens, B., Neufeld, J. D., Verstraete, W., De Lorenzo, V. (2006). Distribution and phylogeny of hexachlorocyclohexane-degrading bacteria in soils from Spain. Environ. Microbiol., 8, 60-68.

Mosmann, T. (1983). Rapid colorimetric assay for cellular growth and survival: application to proliferation and cytotoxicity assays. J. Immunol. Methods, 65, 55-63.

Nalin, R., Simonet, P., Vogel, T. M., Normand, P. (1999). Rhodanobacter lindaniclasticus gen. nov., sp. nov., a lindane-degrading bacterium. Int. J. Syst. Bacteriol., 49, 19-23.

Nayyar, N., Sangwan, N., Kohli, P., Verma, V., Kumar, R., Negi, V., Oldach, P., Mahato, N. K., Gupta, V., Lal, R. (2014). Hexachlorocyclohexane: persistence, toxicity and decontamination. Rev. Environ. Health, 29, 4952.

Nielsen, A. T., Tolker-Nielsen, T., Barken, K. B., Molin, S. (2000). Role of commensal relationships on the spatial structure of a surface-attached microbial consortium. Environ. Microbiol., 2, 59-68.

Pelz, O., Tesar, M., Wittich, R. M., Moore, E. R. B., Timmis, K. N., Abraham, W.-R. (1999). Towards elucidation of microbial community metabolic pathways: unravelling the network of carbon sharing in a pollutantdegrading bacterial consortium by immunocapture and isotopic ratio mass spectrometry. Environ. Microbiol., 1, 167-174.

Phillips, T. M., Seech, A. G., Lee, H., Trevors, J. T. (2005). Biodegradation of hexachlorocyclohexane (HCH) by microorganisms. Biodegradation, 16, 363-392. 
Sahu, S. K., Patnaik, K. K., Sharmila, M., Sethunathan, N. (1990). Degradation of alpha-, beta-, and gammahexachlorocyclohexane by a soil bacterium under aerobic conditions. Appl. Environ. Microbiol., 56, 36203622.

Sambrook, J., Russell, D. W. (2001). Molecular cloning. A laboratory manual. 3rd edition. New York: Cold Spring Harbor Laboratory Press.

Schachter, B. (2003). Slimy business - the biotechnology of biofilms. Nat. Biotechnol., 21, 361-365.

Schmalenberger, A., Schwieger, F., Tebbe, C. C. (2001). Effect of primers hybridizing to different evolutionarily conserved regions of the small-subunit rRNA gene in PCR-based microbial community analyses and genetic profiling. Appl. Environ. Microbiol., 67, 3557-3563.

Schwieger, F., Tebbe, C. C. (1998). A new approach to utilize PCR-single-strand-conformation polymorphism for 16S rRNA gene-based microbial community analysis. Appl. Environ. Microbiol., 64, 4870-4876.

Sievers, F., Wilm, A., Dineen, D., Gibson, T. J., Karplus, K., Li, W., Lopez, R., McWilliam, H., Remmert, M., Söding, J., Thompson, J. D., Higgins, D. G. (2011). Fast, scalable generation of high-quality protein multiple sequence alignments using Clustal Omega. Mol. Syst. Biol., 7, 539.

Singh, B. K., Kuhad, R. C., Singh, A., Tripathi, K. K., Ghosh, P. K. (2000). Microbial degradation of the pesticide lindane (gamma-hexachlorocyclohexane). Adv. Appl, Microbiol., 47, 269-298.

Tamura, K., Stecher, G., Peterson, D., Filipski, A., Kumar, S. (2013). MEGA6: Molecular Evolutionary Genetics Analysis version 6.0. Mol. Bio. Evol., 30, 2725-2729.

Tillmann, S., Strömpl, C., Timmis, K. N., Abraham, W.-R. (2005). Stable isotope probing reveals the dominant role of Burkholderia sp. in aerobic degradation of PCBs. FEMS Microb. Ecol., 52, 207-217. 